\title{
DINAMIKA IDIOLOGI PEREMPUAN DALAM KUMPULAN CERPEN LUH-LUH KARYA I MADE SUARSA
}

\author{
I Ketut Sudewa \\ I Made Suarsa \\ Prodi Sastra Indonesia, Fakultas Ilmu Budaya, \\ Universitas Udayana \\ Email: sudewa.ketut@yahoo.co.id
}

\begin{abstract}
Various ideologies are expressed by the author in the literary works he created. One of the modern Balinese literary authors, I Made Suarsa in his short story entitled Luh-Luh reveals the dynamics of female ideology. The dynamics of women's ideology reflect the ideology of Indonesian women from various professions and are expressed by authors in various styles of language. The problems discussed in this research are: (1) how the dynamics of women's ideology in the story of Luh-Luh short story by I Made Suarsa; and (2) how the author discloses the woman's ideology in her story collection. Theories used to answer the above problems are feminist theory, ideology, and sociology of literature. The research method used is qualitative method through literature study, descriptive analytics, and descriptive. Techniques used are techniques of referring, notes, and tafseer. The results show that women's ideology is seen from three professions, namely: politician (legislative), artist, and state official (executive). The dynamics of women's ideology are expressed by the author through the style of metaphorical language, pleonasm, and comparison. In addition, the author also uses sound games to reinforce the image the author wishes to convey.
\end{abstract}

Keywords : dynamics, ideology, women

\section{PENDAHULUAN}

Latar belakang penelitian ini berangkat dari suatu asumsi dasar bahwa setiap karya sastra yang diciptakan oleh pengarang ada pesan, amanat, atau idiologi yang ingin disampaikan oleh pengarang. Asumsi ini berdasarkan suatu anggapan bahwa karya sastra adalah ciptaan pengarang, baik sebagai individu maupun sebagai mahluk sosial. Pengarang dalam konteks tersebut tentu saja memiliki pesan dan ide yang ingin diungkapkan kepada masyarakat pembaca melalui karya sastra yang diciptakan berdasarkan renungan peribadi atau hasil interaksi dengan lingkungan sosialnya. Berdasarkan realitas tersebut, maka Damono (1978:1) mengatakan bahwa karya sastra menampilkan gambaran kehidupan dan kehidupan itu sendiri adalah suatu kenyataan sosial. Kenyataan sosial yang dihadapi oleh pengarang diolah berdasarkan kemampuan imajinasi yang dimilikinya. Hasil olahan inilah yang diwujudkan ke dalam bentuk karya sastra.

Dalam konteks penelitian ini, dinamika idiologi perempuan yang diungkapkan oleh I Made Suarsa di dalam kumplan cerpen Luh-Luh tentu saja berdasarkan renungan dan ide peribadi pengarang dan berdasarkan hasil interaksinya dengan lingkungan sosialnya. Penelitian terhadap dinamika idiologi perempuan, khususnya di dalam karya sastra penting dilakukan mengingat dalam kenyataan, idiologi-idiologi perempuan jarang dibahas dan diteliti, padahal hal tersebut urgen di dalam menyusun kebijakan dalam membangun kesetaraan gender. Dengan penelitian ini tidak hanya dapat menemukan idiologi perempuan di mata pengarang, tetapi juga idiologi perempuan dalam masyarakat sebagai tanda-tanda zamannya. 
Berdasarkan latar belakang di atas, maka permasalahan yang dibahas di dalam penelitian ini adalah: (1) bagaimana dinamika idiologi perempuan di dalam kumpuan cerpen Luh-Luh karya I Made Suarsa; dan (2) bagaimana cara pengarang mengungkapkan idiologi perempuan tersebut di dalam kumpulan cerpennya. Dengan dua permasalahan ini diharapkan dapat mengungkapkan dinamika idiologi perempuan di dalam kumpulan cerpen Luh-Luh karya I Made Suarsa. Teori yang diunakan adalah teori sosiologi sastra, feminim, dan teori idiologi.

Tujuan khusus penelitian ini berkaitan dengan permasalahan yang telah ditentukan, yaitu untuk menemukan dinamikan idiologi perempuan yang diungkapkan oleh pengarang di dalam kumpulan cerpen Luh-Luh. Di samping itu, untuk menemukan cara dan teknik pengarang di dalam mengungkapkan dinamika idiologi perempuan di dalam karya sastranya tersebut. Dengan tujuan khusus tersebut hasilnya diharapkan berguna dalam menyusun kebijakan yang berkaitan dengan kesetaraan gender.

\section{METODE PENELITIAN}

Metode penelitian yang digunakan dalam penelitian ini adalah metode kualitatif. Metode ini menekankan pada kualitas data bukan kuantitas data dengan cara kerja studi pustaka dan teknik hermeneutik (penafsiran) secara logis dan bernalar. Pengumpulan data dilakukan dengan cara membaca, mengklasifikasi, dan mengidentifikasi objek penelitian sesuai dengan permasalahan yang ditetapkan, yakni data tentang idiologi perempuan di dalam objek penelitian. Setelah itu, pada tahap analisis data, dilakukan dengan cara menafsirkan data yang berkaitan dengan permasalahan melalui teori yang ditetapkan. Hasil analisis data disusun ke dalam format penelitian Hibah Unggulan Program Studi sesuai dengan yang telah ditetapkan secara deskriptif dengan memakai bahasa Indonesia ragam ilmiah.

\section{HASIL DAN PEMBAHASAN}

Sebelum dilakukan analisis atau pembahasan terhadap permasalahan yang telah ditetapkan, maka terlebih dahulu dibahas tentang teori yang digunakan dalam penelitian ini. Teori dimaksud diuraikan secara garis besarnya saja sehingga ada gambaran umum tentang teori tersebut.

Untuk membahas dinamika idiologi perempuan di dalam kumpulan cerpen Luh-Luh karya I Made Suarsa akan digunakan teori feminis, idiologi, dan sosiologi sastra. Dengan teori-teori ini diharapkan permasalahan yang ditentukan dapat dipecahkan dan dapat menghasilkan penelitian yang valid dan dapat dipertanggungjawabkan secara ilmiah. Oleh karena keterbatasan ruang dan waktu, maka tinjauan pustaka akan dikemukakan yang urgen saja, sedangkan yang bersifat menunjang akan diungkapak ketika dilakukan analisis.

Kajian sastra dengan menggunakan teori feminisme jarang dilakukan mengingat kesetaraan gender bagi kaum perempuan sudah tidak lagi menjadi permasalahan atai isu yang menarik dewasa ini. Akan tetapi dalam penelitian ini teori ini berkontribusi dalam melihat dinamika idiologi dari sudut feminism di dalam karya sastra.

Munculnya teori feminism berkaitan dengan munculnya kesadaran perempuan terhadap hak dan kewajibannya sebagai maunusia individu dan manusia kolektif atau sosial. Indikator bangkinya feminism menurut Kutha Ratna (2007:408) adalah: (1) kemajuan teknik kontrasepsi yang memungkinkan kaum perempuan membebaskan diri dari tugas rumah tangga; (2) kemajuan pendidikan; (3) sebagai reaksi terhadap pendekatan strukturalisme yang melepaskan diri dari konteks sosial; (4) sebagai reaksi terhadap kekuasaan tradisi; dan (5) sebagai reaksi terhadap visi marxisme ortodoks.

Kajian feminisme terhadap karya sastra akan meneliti sejauhmana konsep perempuan terungkap di dalam karya sastra dan di sisi lain, melihat sejauh mana kaum perempuan terlibat di dalam proses penciptaan karya sastra. Menurut Kutha Ratna (2007:411) kritik sastra feminisme adalah membaca dan menilai karya sastra sebagai 
perempuan. Pada dasarnya jenis kelamin, yaitu laki-laki dan perempuan berpengaruh besar dalam proses analisis masalah, khususnya dalam analisis karya sastra. Dalam konteks penelitian ini akan diungkapkan gambaran perempuan beserta idiologi perempuan yang tergambar di dalam objek penelitian ini. Perempuan dan laki-laki tidak hanya berbeda dalam hal jenis kelamin tetapi juga dalam hal idiologi dalam menyikapi perkembangan zaman.

Idiologi dalam konteks penelitian ini adalah konsep atau pikiran-pikiran dari seseorang atau kelompok orang yang berpengaruh terhadap lingkungan sosialyang lebih luas yangmenimbulkan gerakan tertentu. Idiologi adalah seperangkat keyakinan, prinsip tertentu yang mengarahkan perilaku individi dan kelompok tertentu (Kutha Ratna, 2013:176). Dalam konteks penelitian ini akan dilihat keyakinan atau prinsip setiap tokoh perempuan yang ada di dalam objek penelitian ini, kemudian perilakunya di dalam mengekspresikan keyakinan dan prinsipnya tersebut.

Dasar pemikiran munculnya teori sosiologi sastra adalah bahwa tidak ada karya sastra yang dicptakan dalam kekosongan budaya. Artinya, tidak ada karya sastra yang berfungsi dalam situasi kosong. Setiap karya sastra merupakan aktualisasi atau realisasi tertentu dari sebuah sistem konvensi atau kode sastra dan budaya (Teeuw, 1980:11) atau karya sastra merupakan refleksi dari realitas (Junus,1978:7). Dalam konteks penelitian ini, dipandang bahwa objek penelitian ini (kumpulan cerpen Luh-Luh) adalah refleksi dari kenyataan sosial yang diamati oleh pengarang, kemudian dituangkan ke dalam karya sastra melalui proses kreatif dan imajinasi.

Berdasarkan pandangan sosiologis di atas, maka teori sosiologi sastra yang relevan digunakan dalam penelitian ini adalah teori dari Diana Laurenson Alan Swingewood (1972:1622). Dikatakan bahwa analisis sosilogi sastra menyangkut tiga perspektif, yaitu: (1) sosiologi sastra tidak hanya bertugas untuk menemukan sejarah dan refleksi sosial yang ada dalam karya sastra, tetapi juga harus mampu menemukan fakta-fakta dalam karya sastra bersangkutan; (2) sosiologi sastra memandang karya sastra sebagai sebuah produksi, khsusnya tentang situasi sosial pengarangnya; dan (3) sosiologi sastra berusaha menemukan jejak-jejak dalam karya sastra yang dapat diterima sebagai fakta sosial. Diperjelas lagi oleh Kutha Ratna (2004:60) bahwa hubungan karya sastra dengan masyarakatnya disebabkan oleh: (1) karya sastra dihasilkan oleh pengarang; (2) pengarang adalah anggota masyarakat; (3) pengarang memanfaatkan keadaan sosial yang ada dalam masyarakat; dan (4) hasil karya sastra dimanfaatkan kembali oleh masyarakat. Dalam konteks penelitian ini, objek penelitian dipandang sebagai fakta yang mengandung jejak-jejak berupa dinamika idiologi perempuan sebagai suatu fakta sosial dalam masyarakat.

Ada berbagai idiologi perempuan yang diungkapkan oleh pengarang di dalam kumpulan cerpen Luh-Luh tersebut. Idiologi-idiologi tersebut merupakan dinamika perempuan di Indonesia dari kaca mata I Made Suarsa. Dinamika tersebut membentuk opini pembaca terhadap kehidupan perempuan di Indonesia pada saat ini dan di masa mendatang. Dari judul cerpen sudah menunjukkan bahwa semua cerpen (19 cerpen) mengungkapkan tentang kehidupan kaum perempuan karena kata Luh-Luh (bahasa Bali) berarti para perempuan. Kaum perempuan tersebut berasosiai dengan perempuan yang menjadi tokoh masyarakat (public figure) di Indonesia, seperti: politisi, artis, dan pejabat. Adapun dinamika idiologi perempuan yang diungkapkan oleh pengarang diuraikan sebagai berikut.

\section{1) Perempuan Politisi (legislatif)}

Di dalam kumpulan cerpen Luh-Luh karya I Made Suarsa, salah satu idiologi yang diungkapkan oleh pengarang adalah tentang perempuan sebagai politisi atau pejabat negara. Dalam konteks ini, pengarang secara tidak langsung mengungkapkan tentang idiologi kesetaraan gender di dalam kehidupan berbangsa dan bernegara. Di dalam cerpen berjudul "Luh Enji" yang diasosiasikan sebagai politisi perempuan yang sedang dipenjara karena kasus korupsi, yaitu Engelina Sondahk (panggilannya "Enji"). Di dalam cerpen ini, 
pengarang mengungkapkan idiologi perempuan politisi yang kaya, selalu tampil cantik, dan memiliki teori yang tinggi tentang cara menjadi perempuan yang baik di keluarga dan masyarakat dan suka menerima suap (uang dalam amplop). Akan tetapi, tidak bisa melaksanakannya. Pengarang menyampaikannya seperti kutipan berikut.

Inggih ibu-ibu, dados anak istri wantah paduman. Paduman dados ayah, ngayahin somah ngayahin pianak gelah. Sakemaon iraga tetep mlajah, mangde nenten terus ketandes, ten terus kalah. Iraga mangda dueg, mangda jegeg antuk ngupapira angga, manda mataksu antuk nganutin tata titi awig-awig.

Lengut tur lemuh pisan Luh Enji mapidarta, wastu suryake makuug. Ibu-ibu masliweran sami dot mapotrek sareng, ibuibu panitia taler bincuh nampekin Luh Enji sane sedek kagarang olih ibu-ibu, nesekin sinambi nyerahan amplop coklat sada kembung, pastika masegseg madaging jinah

(Suarsa, 2016:3)

Terjemahannya:

Ya ibu-ibu, menjadi perempuan adalah takdir.Takdir menjadipeladen, meladenisuami dan anak. Akan tetapi, kita harus tetap belajar supaya tidak ditindas, tidak selalu kalah. Kita harus pintar, cantik dan memelihara tubuh, supaya berwibawa dan mengikuti peraturan. Lembut dan meyakinkan Luh Enji berbicara membuat pendengar riuh bertepuktangan. Ibu-ibu sibuk, semua ingin berfoto bersama, ibu-ibu panitia juga sibuk mendekati Luh Enji ketika dikerumuni oleh ibu-ibu, mendekat sambil menyerahkan amplop berwarna coklat yang besar karena di dalamnya ada banyak uang.

Kutipan di atas sebagai penanda menunjukkan adanya idiologi bahwa perempuan modern (pejabat negara) harus tampil cantik, bisa berpidato yang hebat untuk meyakinkan orang (sebagai petanda). Petanda lainnya bahwa politisi yang cantik dan ramah akan diidolakan oleh masyarakat, walaupun masyarakat akhirnya harus memberi uang sogokan (amplop) dan Luh Enji sebagai tokoh masyarakat dan anggota DPR senang menerima uang sogokan. Perilaku seperti inilah yang menyebabkan Luh Enji berhenti menjadi anggota DPR dan dipenjarakan karena kasus korupsi.

\section{2) Perempuan Artis}

Idiologi perempuan juga diungkapkan oleh pengarang melalui tokoh artis. Tokoh artis tersebut juga dapat diasosiakan dengan artis terkenal di Indonesia. Pengarang tampaknya secara detil mengamati idiologi di balik sepak terjang para artis di Indonesia. Misalnya, dalam cerpen berjudul "Luh Tingting". Tokoh utama dalam cerpen ini adalah Luh Tingting yang diasosiaikan dengan artis terkenal di Indonesia, yaitu Ayu Tingting. Idiologi perempuan di balik sepak terjang Luh Tingting sebagai artis adalah bahwa perempuan, walaupun cantik dan terkenal harus memiliki keuletan dan prinsip hidup yang kuat serta bertanggungjawab terhadap kehidupan keluarga. Misalnya, Luh Tingting (sebelum menjadi artis bernama Luh Canting) bekerja keras untuk menghidupi keluarganya dan menyekolahkan adik-adiknya. Pengarang menggambarkan keadaan Luh Tingting (Luh canting) melalui narasi berikut.

Yadiastunyusane sampun nepek slae tiban, Luh Canting durung taler naenin madrebe gegelan. Boya sangkaning ipun bocok, nanging saking uleng geleng degeng ngrereh pangupa jiwa, nyarengin rerama ngupapira adin-adinipune, Ni Made Sibuh, I Nyoman Sangku mangda sida masekolah setegehtegehnyane. Maweweh malih rencana ngajak rerama matirta yatra ka jagat India, telas galahnyane anggen nguber jinah, wastu nenten wenten selah ngitungang gagelan.

(Suarsa, 2016:13)

Terjemahannya:

Walaupun usianya hampir 25 tahun, Luh Canting belum pernah mempunayi pacar. Bukan karena ia tidak cantik, namun karena fokus pikirannya untuk bekerja membantu orangtuanya untuk menghidupi dan 
menyekolahkan adik-adiknya, Ni Made Sibuh, I Nyoman Sangku setinggi-tingginya. Ditambah lagi rencananya mengajak orangtuanya matirta yatra ke India, habis waktunya untuk mencari uang dan tidak sempat memikirkan pacar.

Dari kutipan narasi di atas sebagai penanda tampak pengarang menggambarkan idilogi perempuan artis yang selalu bekerja keras dan bertanggungjawab kepada keluarganya. Luh Tingting bekerja keras mencari uang, bahkan tidak sempat memikirkan dirinya sebagai perempuan yang suatu saat harus menikah. Petanda dari penanda di atas adalah Luh Tinting sebagai perempuan yang bertanggungjawab kepada keluarga. Dengan gaya pleonasme pengarang menggambarkan hal tersebut dengan menulis: "telas galahnyane anggen nguber jinah, wastu nenten wenten selah ngitungang gagelan". Di sisi yang lain, pengarang juga mengungkapkan idiologi lain dari perempuan artis melalui tokoh Luh Tingting, yakni perempuan harus setia dan mampu hidup mandiri walaupun harus menghidupi anaknya sendiri tanpa suami karena ditinggal pergi.

\section{3) Perempuan Pejabat (Eksekutif)}

Idiologi perempuan juga dimunculkan oleh pengarang melalui tokoh perempuan pejabat eksekutif (menteri). Hal ini tampak di dalam cerpen berjudul "Luh Susy". Toko utama cerpen ini adalah Luh Susy yang diasosiasikan dengan Menteri Kelautan dan Perikanan Indonesia, yakni Susi Puji Astuti. Luh Susy adalah perempuan yang hidup dari keluarga nelayan. Ia hanya mau masuk sampai SMP saja tidak mau melanjutkan sekolah. Ia lebih memilih membantu orangtuanya berdagang ikan laut di pinggir pantai daripada melanjutkan sekolah ke SMA. Pengarang menggambarkan keadaan tersebut seperti kutipan berikut.

Tatkalaning timpal-timpalnyane sami, siswa-siswi muputang sekolah SMP PGRI, kumu migarangin SMA Negeri, Luh Susy nios-nios padidi, kekeh jroning hati, nglatur masekolah nenten jagi, boya ngelidin brahmacari Saraswati, nanging cumpu nyarengin yayah bibi, madolan ulam ring TPI.

"Luh jani suba tamat SMP, kema tuah ngalih sekolah buin, apang bantas tamat SMA!".

"Ten Pa, kanggeang tiang tamat SMP dogen".

"Nguda keto ning? Meme nu nyidaang nanggung Luh kanti tamat SMA cara tutur Bapan Luhe".

"Banggeang me.Ngadenantiang marengin meme ajak bapa madagang be di pasisi”.

Ping telu pang pat katuturin. Luh Susy teteg mamengkeng, tetep mamengkung, beduk sinduk tan dados keleg, wastu meme bapannyane nyerah kalah. Malah walik, Luh Susy mangkin nuturin adinnyane makakalih.

(Suarsa, 2016:73)

\section{Terjemahannya:}

Sewaktu teman-temannya semua menamatkan sekolah di SMP PGRI, semua berebut mencari sekolah SMA Negeri, Luh Susy berbeda sendiri. Tekad hatinya tidak akan melanjutkan sekolah, tidak karena malas belajar, tetapi karena keinginannya untuk membantu orang tuanya berjualan ikan di TPI.

"Luh, sekarang sudah tamat SMP, ayo cari sekolah lagi, supaya setidaknya tamat SMA".

"Tidak pak, biar saya tamat SMP saja".

"Mengapa begitu nak? Ibu masih bisa membiayai kamu sekolah sampai tamat SMA seperti kata ayahmu".

"Biarlah bu, lebih baik saya ikut ibu dan bapak berjualan ikan di pantai”.

Berkali-kali dinasihati. Luh Susy tetap saja pada pendiriannya, akhirnya bapaknya menyerah juga. Justru Luh Susy berbalik menasihati adiknya agar mau melanjutkan sekolah.

Kutipan di atas sebagai penanda yang menunjukkan kesederhanaan pikiran Luh Susy. Petanda dari penanda tersebut adalah bahwa seorang 
perempuan anak yang paling tua seharusnya bisa membantu pekerjaan orangtuanya dan mau mengorbankan keingainannya sendiri untuk keluarga, khususnya untuk adik-adiknya. Luh Susy adalah tokoh yang mengerti keadaan ekonomi keluarga dan bertanggungjawab terhadap keluarga dan adik-adiknya. Di samping itu, Luh Susy juga adalah perempuan yang memiliki pendirian yang kuat dan kokoh: "Luh Susy teteg mamengkeng, tetep mamengkung, beduk sinduk tan dados keleg, wastu meme bapannyane nyerah kalah". Hal ini sekaligus menandakan bahwa Luh Susy adalah tokog yang kuat dan pekerja keras.

Keuletan dan kerja keras Luh Susy dalam bekerja menjual ikan di pantai membuat ia menjadi panutan pedagang lainnya. Luh Susy memiliki gagasan membentuk koperasi nelayan sebagai tempat para nelayan memperjuangkan haknya. Terbentuklah koperasi nelayan Mina Mani yang diketuai oleh Luh Susy. Berkat kepemimpinan Luh Susy, koperasi nelayan maju pesat dan terkenal di Bali. Pengarang menggambarkan hal tersebut melalui narasi berikut.

Paguyuban Mina Mani gelis ngelimbak, kasubsajroningjagatBali,sidangrahajengang wong pasisi, pamekas dagang ulam ring pasisi, mrasidayang nabung, nyekolahang pianak, lan kidik-kidik ngayum pakubon. Manut wastane Mina Mani, ulam-ulam sane kaadol satsat mutiara manik, nyambehang amerta ring para angga paguyuban.

Kahanan paguyuban Mina Mani sayan nglimbak, prasida numbas makudangkudang jukung ngatut mesin kalimbakang ring para anggotannyane, ngicen pakebiah dagang-dagang ulam pasisi tiosan sajebag Bali, Pasisi Purnama, Gumicik, Ketewel, Kusamba, Madewi, Pangambengan, miwah sane tiosan. Tan mari paguyuban Mina Mani akeh kasambangin paguyuban tiosan nakenin tata titi ngenterang paguyubane mangda nglimbak sakadi Mina Mani. Akeh pejabat mapaiketan ring indik segara jaladi ngrauhin ngicenin wantuan jinah lan piranti mangda angga paguyuban sayan-sayan bagia rahajeng sadaging kulawargannyane, nenten melarat turun-tumurun

(Suarsa, 2016:75-76)

Terjemahannya:

Koperasi Mina Mani cepat berkembang dan terkenal di Bali, bisa mensejahterakan masyarakat nelayan, terutama pedagang ikan di pantai, bisa menabung, menyekolahkan anak dan memperbaiki rumah. Seperti namanya Mina Mani, ikan yang dijual seperti mutiara memberi rejeki dan kehidupan bagi anggota koperasi.

Koperasi Mina Mani semakin maju, bisa membeli banyak perahu bermesin untuk para anggota koperasi, memberi harapan dan motivasi bagi pedagang ikan di pantai lainnya seluruh Bali, pantai purnama, Gumicik, Ketewel, Kusamba, Madewi, Pangambengan, dan lain-lain.

Sering koperasi Mina Mani dikunjungi oleh koperasi nelayan lainnya untuk studi banding mengenai cara mepimpin dan mengembangkan koperasi supaya terkenal seperti koperasi Mina Mani. Banyak pejabat yang berkaitan dengan koperasi datang memberi bantuan berupa uang dan alat-alat nelayan agar anggota koperasi dan keluarganya semakin sejahtera tidak miskin secara turun temurun.

Penanda kutipan di atas menunjukkan keuletan dan jiwa kepemimpinan Luh Susy terhadap teman-temannya sesama pedagang. Walaupun ia hanya tamatan SMP, tetapi ia memiliki ide yang bagus untuk memajukan kehidupan para nelayan di desanya. Kerja keras yang dilakukan oleh Luh Susy dan kawan-kawan berhasil membawa nama koperasi Mina Mani menjadi koperasi yang patut dicontoh oleh koperasi nelayan lainnya dari berbagai daerah. Berkat adanya koperasi nelayan Mina Mani yang dipimpin oleh Luh Susy, masyarakat nelayan bisa lebih maju dan sejahtera. Berbagai bantuan datang dari pihak-pihak yang menaruh perhatian terhadap keberadaan koperasi ini.

Petanda dari penanda di atas adalah bahwa 
seorang pemimpin yang berhasil tidak tergantung dari pendidikan atau jenis kelamin. Keberhasilan hanya dapat dicapai dengan keyakinan dan kerja keras secara bersama-sama. Hal ini dibuktikan oleh Luh Susy dan menjadi idiologi pemimpin yang akan mampu membuat masyarakat semakin maju dan sejahtera.

Secara simbolik atau tidak langsung pengarang mengungkapkan perjalanan hidup Luh Susy sama dengan perjalanan hidup menteri Perikanan dan Kelautan Susi Puji Astuti. Walaupun bu menteri hanya berpendidikan SMP, tetapi beliau mampu dan behasil meminpin Departemen Perikanan dan Kelautan. Ketegasan, keuletan, disiplin, dan kerja keras menteri Susi Puji Astuti sama dengan Luh Susy di dalam cerpen ini. Idiologi pejabat negara perempuan tampak diungkapkan oleh pengarang melalui tokoh Luh Susy, yakni kerja keras, disiplin, dan percaya diri dalam meminpin dan bekerja akan menjadi modal menuju keberhasilan.

\section{KESIMPULAN}

Dari analisis yang telah dilakukan terhadap kumpulan cerpen Luh-Luh karya I Made Suarsa tampak idiologi perempuan dilihat dari tiga profesi, yakni: politisi (legislatif), artis, dan pejabat negara (eksekutif). Dinamika idiologi perempuan tersebut diungkapkan oleh pengarang melalui gaya bahasa metafora, pleonasme, serta perbandingan. Di samping itu, pengarang juga menggunakan permainan bunyi untuk memperkuat gambaran yang ingin disampaikan oleh pengarang.

Dinamika idiologi perempuan yang tampak dari tiga profesi itu adalah sebagai berikut.

1) Perempuan politisi (legislatif) harus ampil cantik, bisa berpura-pura terhadap rakyat atau pendukungnya dan menampilan yang mewah walaupun harus melanggar hukum, seperti korupsi untuk kepentingan idiologinya

2) Perempuan artis harus cantik, berani mengalami perceraian, kuat dan tabah membesarkan anak apabila ditinggalkan oleh pasangannya, serta bertanggungjawab kepada keluarga.

3) Perempuan pejabat negara (eksekutif) harus berani, tegas, kuat, disiplin, dan percaya diri ketika diberi kepercayaan menjadi pemimpin. Modal ini penting agar lembaga yang dipimpin bisa maju dan berhasil.

\section{UCAPAN TERIMAKASIH}

Penelitian ini selesai karena kerjasama tim peneliti, nara sumber dan berbagai dokumen serta informasi dari berbagai pihak serta penyandang dana. Oleh karena itu, kami sampaikan terima kasih kepada pihak-pihak berikut.

1) Tim peneliti, informan, dan pihak-pihak lain yang telah bekerjasama dengan baik dan telah memberi bantuan dan informasi ynag berguna dalam penelitian ini.

2) Dekan FIB dan Kaprodi Sastra In.donesia yang telah memberikan izin untuk melakukan penelitian

3) Rektor Universitas Udayana melalui LPPM yang telah memberikan dana dalam penelitian ini

\section{DAFTAR PUSTAKA}

Endraswara, Suwardi. 2011. Metodologi Penelitian Sosiologi Sastra. Yogyakarta: CAPS

Kutha Ratna, I Nyoman. 2004. Teori, Metode, Teknik Penelitian Sastra. Yogyakarta: PustakaPelajar

Kutha Ratna, I Nyoman. 2007. Sastra dan Cultural Studies Representasi Fiksi dan Fakta. Yogyakarta: Pustaka Pelajar

Kutha Ratna, I Nyoman. 2013. Glosarium 1.250 Entri Kajian Sastra, Seni, dan Sosial Budaya. Yogyakarta: Pustaka Pelajar

Laurenson, Diana dan Allan Swingewood. 1972. The Sociology of Literature. London:Paladin Junus, Umar. 1978. Sosiologi Sastra Sebuah Pengantar Ringkas. Jakarta: Pusat Pembinaan dan Pengembangan Bahasa

Teeuw, A. 1980. Tergantung Pada Kata. Jakarta: Pustaka Jaya. 